\title{
Topology and seasonal evolution of the network of extreme precipitation over the Indian subcontinent and Sri Lanka
}

\author{
V. Stolbova ${ }^{1,2}$, P. Martin ${ }^{3}$, B. Bookhagen ${ }^{4,5}$, N. Marwan ${ }^{1}$, and J. Kurths ${ }^{1,2,6}$ \\ ${ }^{1}$ PIK Potsdam Institute of Climate Impact Research, P.O. Box 601203, 14412 Potsdam, Germany \\ ${ }^{2}$ Department of Physics, Humboldt-Universität zu Berlin, Newtonstr. 15, 12489 Berlin, Germany \\ ${ }^{3}$ University of Michigan, Ann Arbor, Michigan, USA \\ ${ }^{4}$ Department of Geography, University of California, Santa Barbara, USA \\ ${ }^{5}$ University of Potsdam, Institute of Earth and Environmental Science, Karl-Liebknecht-Str. 24-25, \\ 14476 Potsdam-Golm, Germany \\ ${ }^{6}$ Institute for Complex Systems and Mathematical Biology, University of Aberdeen, Aberdeen, AB243UE, UK
}

Correspondence to: V. Stolbova (stolbova@pik-potsdam.de)

Received: 17 November 2013 - Revised: 17 July 2014 - Accepted: 21 July 2014 - Published: 29 August 2014

\begin{abstract}
This paper employs a complex network approach to determine the topology and evolution of the network of extreme precipitation that governs the organization of extreme rainfall before, during, and after the Indian Summer Monsoon (ISM) season. We construct networks of extreme rainfall events during the ISM (June-September), post-monsoon (October-December), and pre-monsoon (March-May) periods from satellite-derived (Tropical Rainfall Measurement Mission, TRMM) and rain-gauge interpolated (Asian Precipitation Highly Resolved Observational Data Integration Towards the Evaluation of Water Resources, APHRODITE) data sets. The structure of the networks is determined by the level of synchronization of extreme rainfall events between different grid cells throughout the Indian subcontinent. Through the analysis of various complex-network metrics, we describe typical repetitive patterns in North Pakistan (NP), the Eastern Ghats (EG), and the Tibetan Plateau (TP). These patterns appear during the pre-monsoon season, evolve during the ISM, and disappear during the post-monsoon season. These are important meteorological features that need further attention and that may be useful in ISM timing and strength prediction.
\end{abstract}

\section{Introduction}

The Indian monsoon is a large-scale atmospheric pattern and one of the active components in the global climate system in the tropics. It is an important weather phenomenon for other parts of the globe as well, because of the monsoon's coupling with climate drivers such as the El Niño-Southern Oscillation, the Indian Ocean Dipole and the Equatorial Indian Ocean Oscillation (Sankar et al., 2011; Achuthavarier et al., 2012; Sabeerali et al., 2011; Wu and Kirtman, 2003; Wu et al., 2012; Gadgil, 2004). Understanding the structure of the spatial heterogeneity of extreme rainfall during the ISM plays a crucial role in the daily life and prosperity of the Indian population. Spatial rainfall distribution and especially the distribution of extreme rainfall events is a significant question for Indian agriculture and economy, as extreme rainfall is a common cause of floods on the Indian subcontinent. It is therefore essential to track the origins and dynamics of the extreme events. In this study, we find such origins in the topology of networks of extreme rainfall events during the ISM, and the periods before and after the monsoon.

\subsection{ISM, pre-monsoon and post-monsoon seasons of the Indian subcontinent}

Changes in precipitation over the Indian subcontinent during the year can be divided into three phases: the pre-monsoon season (March-May), the main rainy season (the Indian 
Summer Monsoon (ISM) season; June-September), and the post-monsoon season (October-December). During the Indian Summer Monsoon season, the Indian subcontinent receives more than $80 \%$ of its annual rainfall across the region (Bookhagen and Burbank, 2010). During the post-monsoon season, the strongest rainfall covers the southern tip of India and most of Sri Lanka. Pre-monsoon months (MarchMay) are characterized by light rainfall over the Himalaya, the southwestern part of India, and Myanmar (Burma) (see Fig. 1).

The ISM is driven by heating of the high-altitude Tibetan Plateau that leads to a near-surface low-pressure system that attracts moist air from the surrounding oceans, especially the Bay of Bengal (Flohn, 1957; Gadgil, 2003; Webster, 1997). On large scales, the ISM is linked to the seasonal heating of land masse and interacts with the westerly jet stream. An important interaction occurs when the Somali jet stream crosses the Arabian Sea, changing the direction of ocean currents, and when colder water wells up from lower ocean layers, causing a decrease in temperature. Additionally, a lowpressure trough where the southern and northern trade winds meet, a border known as the Intertropical Convergence Zone (ITCZ), moves north. As a result, tropical storms, depressions, cyclones, squall lines and daily cycles become more erratic and thus less predictable. On the eastern peninsula, the differential heating between the Bay of Bengal and the surrounding land masses (including the Tibetan Plateau) constitutes the moisture source of monsoonal rain. These combined factors create a low-pressure "monsoon trough" to the south and parallel to the Himalayan mountains. It is this trough's fluctuations that largely influence when monsoonal rains start and stop, generally considered active and break phases (Gadgil, 2003).

October-December is a period during which the southern part of the Indian peninsula and Sri Lanka receive a major amount of their yearly rainfall. This season is also widely known as the Northeast Monsoon (NEM), winter monsoon (Rao, 1999), or post-monsoon season, which we use in this paper (Singh and Sontakke, 1999), as it refers to a reversal of wind direction. Although differential heating and the resultant thermal circulation are responsible for both the ISM and post-monsoon seasons, the two monsoon seasons differ substantially in several respects (Wang, 2006). First of all, the heat source region of the post-monsoon season is much closer to the equator (Krishnamurti, 1971), where the effect of the Earth's rotation is diminished. Also, the circulation of the post-monsoon season encompasses a larger meridional domain, such that the tropical region has a strong interaction with the extratropical region. During the post-monsoon season, the ITCZ moves south, and jet streams return to their winter locations. The westerly jet stream splits into two: the northern jet stream runs north of the high-elevation Tibetan plateau and continues eastward above China; the southern jet stream runs to the south of the Himalaya. The area of maximum heating moves south to Indonesia, and low-pressure

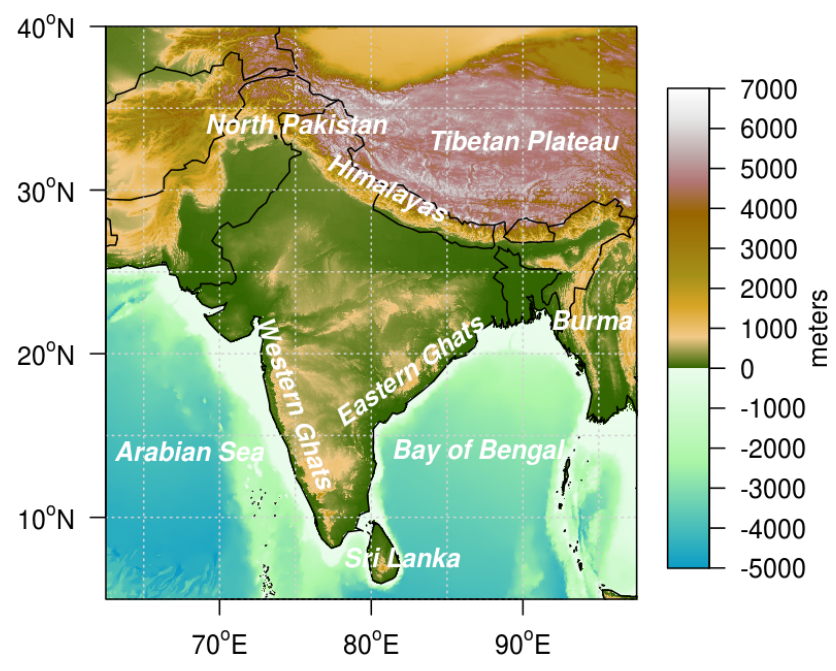

Figure 1. Regional overview of the Indian subcontinent. Major topographic and political features referred to in the text are labeled in white, and the background image is based on the Shuttle Radar Topography Mission (SRTM30) gridded digital elevation model, which is available at GEBCO (2014).

cyclones migrate into the Pacific Ocean. During the postmonsoon season, rainfall across northwestern India, Pakistan, Bangladesh and Nepal is caused by winter westerlies. Precipitation during the winter months is crucial for agriculture, particularly for the rabi crops.

The pre-monsoon season is usually determined to be the period before the ISM (March-May), and is characterized by changes in the temperature and pressure gradients, as well as wind direction - from predominantly northwesterly to southwesterly winds. During this season, climatologists try to predict the onset, strength, and internal variability of the developing ISM. In this study, we focus on special features of the ISM and pre-monsoon seasons, including spatial distribution of the extreme precipitation, temperature and pressure, which determine the coming ISM season.

\subsection{Climate networks as a tool for ISM analysis}

Various approaches exist for studying Indian monsoon dynamics, such as numerical modeling using, for instance, Atmospheric General Circulation Models (AGCMs) (Krishna Kumar, 2005; Waliser et al., 2003), statistical analysis of observational or reanalysis data (Revadekar and Preethi, 2012; Rajkumari and Narasimha, 1996), or recurrence analysis to detect regime transitions (Marwan et al., 2009, 2013) or coupling directions with intersystem recurrence networks (Feldhoff et al., 2013).

The application of complex network theory to analyze different climate phenomena is a new but rapidly growing area of research, where a number of studies have been carried out recently (Donges et al., 2009a, b; Malik et al., 2010, 2011; Tsonis and Roebber, 2004; Tsonis et al., 2006, 2008, 
Table 1. Properties of the data sets. APHRODITE: interpolated rain-gauge data (Yatagai et al., 2009). TRMM 3B42V7: satellite-derived data (Huffman et al., 2007). NCEP/NCAR: reanalysis data (Kalnay et al., 1996).

\begin{tabular}{llll}
\hline Properties & APHRODITE & TRMM & NCEP/NCAR \\
\hline Period & Jan 1951-Dec 2007 & Jan 1998-Dec 2012 & Jan 1949-Dec 2012 \\
Geographical coverage & $\left(62.5-97.5^{\circ} \mathrm{E}, 5-40^{\circ} \mathrm{N}\right)$ & $\left(62.375-97.125^{\circ} \mathrm{E}, 5.125-39.875^{\circ} \mathrm{N}\right)$ & $\left(62.5-97.5^{\circ} \mathrm{E}, 5-40^{\circ} \mathrm{N}\right)$ \\
Spatial resolution & $0.5^{\circ} \times 0.5^{\circ}$ & $0.25^{\circ} \times 0.25^{\circ}$ & $2.5^{\circ} \times 2.5^{\circ}$ \\
Temporal resolution & Daily precipitation & 3 hourly, resampled to daily precipitation & $\begin{array}{l}\text { Daily temperature and pressure anomalies, } \\
\text { seasonal mean of winds } \\
\text { Number of grid points }\end{array}$ \\
\hline
\end{tabular}

2010; Gozolchiani et al., 2008, 2011; Yamasaki et al., 2009; Paluš et al., 2011; Barreiro et al., 2011; Deza et al., 2013, 2014; Martin et al., 2013; Tirabassi and Masoller, 2013). While most of these studies are focused on global climate networks of temperature fields and precipitation (Donges et al., 2009a, b; Tsonis and Roebber, 2004; Tsonis et al., 2006; Gozolchiani et al., 2011; Yamasaki et al., 2008, 2009; Scarsoglio et al., 2013), others consider smaller, regional networks that focus on a specific climate phenomenon of interest, such as El Niño (Tsonis and Swanson, 2008; Gozolchiani et al., 2008), Rossby waves (Wang et al., 2013), continental rainfall in Germany (Rheinwalt et al., 2012), the South American Monsoon System (SAMS) (Boers et al., 2013), and the Indian Summer Monsoon (Malik et al., 2010, 2011; Rehfeld et al., 2012). In the work by Rehfeld et al. (2012) on Indian Summer Monsoon (ISM) dynamics, a paleoclimate network approach has revealed a strong influence of the ISM on the East Asian Summer monsoon during the late Holocene period, but with varying strength according to the warm vs. cold epochs. In Malik et al. (2010, 2011), it was demonstrated that by combining the climate network approach with the event synchronization method, it is possible to identify regions that receive rainfall only during the most active phase of the Indian Summer Monsoon. Also, identification of the structure and organization, and in particular the spatial discontinuity of the rain field, was shown, and a predictability scheme for the synchronization of extreme rainfall was introduced. These studies were based on data sets covering only the land area and only for the Indian political boundaries. Since the time that these studies were published, new high-quality data sets have become available for larger regions, including rainfall over the ocean, which we employ in this work.

The question of the spatial structure and organization of present-day extreme rainfall during the pre-monsoon and post-monsoon periods, however, remains open. Additionally, the spatial scale and teleconnections of regions that receive extreme rainfall causing floods over the Indian subcontinent and Sri Lanka during the pre-monsoon, monsoon, and postmonsoon seasons have not yet been revealed. In this paper, we aim to explore the seasonal evolution of the synchronization of extreme rainfall events over the Indian subcontinent and Sri Lanka. In order to address this aim, we first construct and analyze climate networks of extreme rainfall during three seasons: pre-monsoon, ISM, and post-monsoon. Second, we reveal the dominant patterns of synchronized extreme rainfall events over the Indian subcontinent, which occur before the monsoon, develop during the monsoon season, and disappear after the monsoon. Third, we compare dominant patterns with wind fields to establish a linkage to atmospheric processes.

\section{Data and methods}

\subsection{Data}

We use observational satellite data from 1998 to 2012 from the Tropical Rainfall Measuring Mission (TRMM 3B42V7) (Huffman et al., 2007; TRMM, 2014), with a spatial resolution of $0.25^{\circ} \sim 25 \mathrm{~km}$ and a temporal resolution of $3 \mathrm{~h} \mathrm{ag-}$ gregated to daily data. We have extracted data for the South Asian region $\left(62.375-97.125^{\circ} \mathrm{E}, 5.125-39.875^{\circ} \mathrm{N}\right.$; see Table 1 and Fig. 1). This data set is the most recent precipitation data product available. It has a high spatial resolution and covers both land and sea. By the time of this study, however, there are only 15 years of data.

To confirm the significance of the results of this study, we analyze reanalysis gridded daily rainfall data for a time period of 57 years (1951-2007) (Asian Precipitation Highly Resolved Observational Data Integration Towards the Evaluation of Water Resources, APHRODITE) (Yatagai et al., 2009). This data set forms a reliable reanalysis product; however, it is given only for the land masses, excluding the ocean. We have extracted the data for the same region $\left(62.5-97.5^{\circ} \mathrm{E}, 5-40^{\circ} \mathrm{N}\right)$ with a resolution of $0.5^{\circ} \sim 56 \mathrm{~km}$ (APHRO-V1003R1) (see Table 1). This data set was used previously in Malik et al. (2010, 2011) to study the spatial variability of the extreme Indian rainfall during the ISM period using the method of Event Synchronization (ES). In this study, we compare results with previous findings for the ISM season and determine geographic patterns of extreme precipitation over the Indian subcontinent during the premonsoon, monsoon, and post-monsoon seasons. We compare geographic patterns based on precipitation data sets with patterns of temperature and pressure networks derived from reanalysis gridded daily data provided by the National 
Center for Environmental Prediction and the National Center for Atmospheric Research (NCEP/NCAR) (Kalnay et al., 1996; NCEP/NCAR, 2014). In addition, we compare our results with wind fields using reanalysis gridded seasonal mean wind data, also provided by NCEP/NCAR (Kalnay et al., 1996; NCEP/NCAR, 2014). The spatial resolution of the data is $2.5^{\circ}$. The data are extracted for (roughly) the same region as for the APHRODITE data (see Table 1), and contain both land and ocean points in the considered region.

\subsection{Methods}

We consider separately time series of rainfall events, temperature and pressure fields for three time periods: (i) premonsoon, (ii) ISM, and (iii) post-monsoon. The premonsoon period (March, April, May - MAM) is defined as the period from 1 March to 31 May for each year, and consists of 92 days per year. This number multiplied by the number of years in the data set gives the length of the time series for each node in the MAM period. The monsoon period (JJAS) is defined as the period from 1 June to 30 September for each year, and consists of 122 days per year. The postmonsoon period (OND) is defined as the period from 1 October to 31 December for each year, and consists of 92 days per year. The time series at each node for the JJAS and OND periods are computed in the same manner as for the MAM period.

\subsubsection{Event Synchronization (ES)}

Considering rainfall time series, it is important to choose an appropriate method to infer similarity of dynamics between different geographical sites. Rainfall time series are not as smooth and continuous as those for temperature or pressure fields, but often contain a high-frequency component. In this study, we use ES as a method for climate network construction from precipitation data, as proposed in Malik et al. (2010). This method has advantages over other time-delayed correlation techniques (e.g., Pearson lag correlation), specifically for studying precipitation data, as it allows us to define extreme event series of rainfall, depending on the kind of extreme, and uses a dynamic time delay. The latter refers to a time delay that is adjusted according to the two time series being compared, which allows for better adaptability to the region of interest. Another advantage of this method is that it can also be applied to a non-Gaussian and event-like data sets.

We begin by extracting an event series, which is merely a time series that includes only the highest daily rainfall amounts, which we call "extreme events". In the realm of hydrology and climate sciences, extreme rainfall events are days that receive rainfall amounts that exceed the 90th percentile for all days in the time series at a given grid point (see Fig. 2). This threshold thus gives a unique amount of rainfall per day for each grid site. Only the daily rainfall events that are above this threshold for a given site are considered to be extreme rainfall events, and are what make up an event series.

To determine the synchronization between two grid points, let us consider two grid sites, $i$ and $j$. An event $l$ that occurs at a grid site $i$ at time $t_{l}^{i}$ is considered to be synchronized with an event $m$ that occurs at a grid site $j$ at time $t_{m}^{j}$ within a time lag $\pm \tau_{l m}^{i j}$ if $0<t_{l}^{i}-t_{m}^{j}<\tau_{l m}^{i j}$, where $\tau_{l m}^{i j}=\min \left\{t_{l+1}^{i}-t_{l}^{i}\right.$, $\left.t_{l}^{i}-t_{l-1}^{i}, t_{m+1}^{j}-t_{m}^{j}, t_{m}^{j}-t_{m-1}^{j}\right\} / 2$. Here, $l=1,2, \ldots, s_{i}$, $m=1,2, \ldots, s_{j}$, where $s_{i}$ and $s_{j}$ are the number of events at the $i$ th and $j$ th grid sites. Then, for each grid site, we count the number of times when an event occurs at $j$ after $i: c(i \mid j)=\sum_{l=1}^{s_{i}} \sum_{m=1}^{s_{j}} J_{i j}$, and vice versa: $c(j \mid i)$. Here, $J_{i j}$ is an event that happens at place $j$ after place $i$ within the time lag $\pm \tau_{l m}^{i j}$ :

$J_{i j}= \begin{cases}1, & \text { if } 0<t_{l}^{i}-t_{m}^{j} \leq \tau_{l m}^{i j}, \\ 1 / 2, & \text { if } t_{l}^{i}=t_{m}^{j}, \\ 0, & \text { else. }\end{cases}$

We then define the strength of synchronization

$Q_{i j}=\frac{c(i \mid j)+c(j \mid i)}{\sqrt{\left(s_{i}-2\right)\left(s_{j}-2\right)}}$

between events at different grid sites $i$ and $j$, and normalize it to be $0 \leq Q_{i j} \leq 1$. Here, $Q_{i j}=1$ means complete synchronization, and $Q_{i j}=0$ is the absence of synchronization. After repeating this procedure for all pairs $(i \neq j)$ of grid sites, we obtain a correlation matrix. In this case, the correlation matrix for precipitation data is a square, symmetric matrix, which represents the strength of synchronization of the extreme rainfall events between each pair of grid sites.

\subsubsection{Pearson correlation}

In order to compare spatial patterns of extreme rainfall with spatial patterns of temperature and pressure fields, we also construct networks for these fields using NCEP/NCAR data. First, we remove the seasonal cycle by subtracting the longterm daily mean from the daily gridded temperature (pressure) data. We then use a zero-lag Pearson correlation coefficient as a measure of similarity between the nodes, as, for example, in Donges et al. (2009a).

\subsubsection{Network construction}

Applying a certain threshold or link density, we yield an adjacency matrix

$A_{i j}= \begin{cases}1, & \text { if } Q_{i j} \geq \theta_{i j}^{Q}, \\ 0, & \text { else. }\end{cases}$

Here, $\theta_{i j}^{Q}$ is a chosen threshold (see Sect. 2.2.4), and $A_{i j}=1$ denotes a link between the $i$ th and $j$ th sites, and 0 denotes otherwise. The adjacency matrix represents a climate 

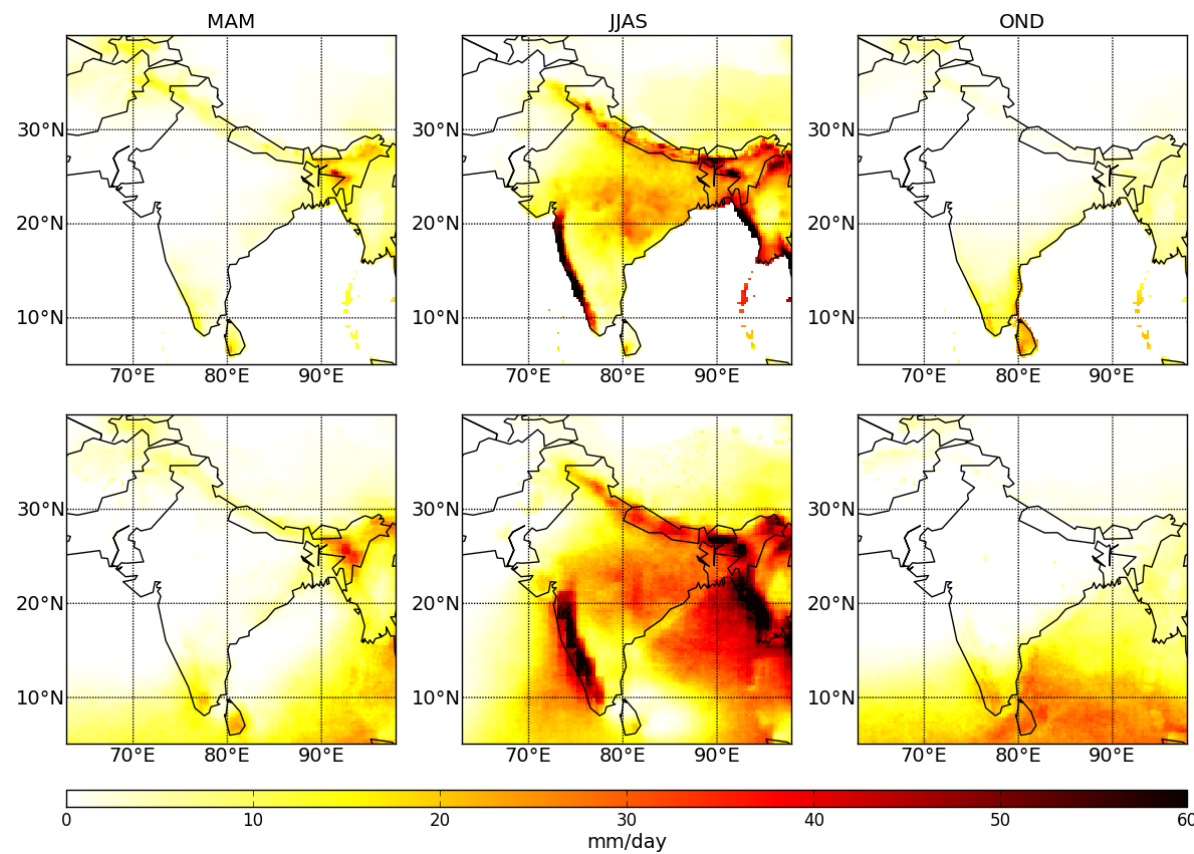

Figure 2. 90th percentile of daily rainfall amounts for the pre-monsoon (MAM), monsoon (JJAS), and post-monsoon (OND) periods for the APHRODITE (top) and TRMM (bottom) data sets using the same color scale.

Table 2. Network measures. $N$ - total number of nodes. $D_{j}$ - degree of a node $j . B_{v}$ - betweenness of a node $v . L_{i j}-$ geographical link length between nodes $i$ and $j$. ALL $i$ - average geographical link length of a node $i$. MLL $\mathrm{L}_{i}$ - maximal geographical link length of a node $i$. $\sigma_{v}(i, j)$ - the number of shortest paths between nodes $i$ and $j$ passing through node $v . \sigma(i, j)-$ total number of shortest paths between $i$ and $j . \alpha_{i j}$ - angular geographical distance. $R$ - radius of the Earth, 6371.009.

\begin{tabular}{llll}
\hline Degree, $D_{i}$ & Betweenness, $B_{v}$ & Average geographical link length, $\mathrm{ALL}_{i}$ & Maximal geographical link length, $\mathrm{MLL}_{i}$ \\
\hline$D_{i}=\frac{\sum_{n=1}^{N} A_{i j}}{N-1}$ & $B_{v}=\sum_{i \neq j \neq v \in\{V\}}^{N} \frac{\sigma_{v}(i, j)}{\sigma(i, j)}$ & $\operatorname{ALL}_{i}=<L_{i j}>_{j}=<\alpha_{i j} A_{i j} R>_{j}$ & $\operatorname{MLL}_{i}=\max \left(L_{i j}\right)_{j}=\max \left(\alpha_{i j} A_{i j} R\right)_{j}$ \\
\hline
\end{tabular}

network, and complex network theory can subsequently be employed to reveal properties of the given network (see Table 2).

In this study, we use an undirected network; i.e., we do not consider which of the two synchronized events happened first, to avoid the possibility of misleading directionalities of event occurrences at grid sites that are topographically close.

\subsubsection{Thresholding}

To include only statistically significant correlations, we choose the $5 \%$ strongest correlations and construct climate networks. We use $5 \%$ as our threshold, since it satisfies both necessary conditions: a high correlation and a sufficient number of extreme events for comparison. Details of network construction and thresholding are given in Table 3.

For temperature networks, the thresholds of the Pearson correlation coefficient are $0.19,0.15$, and 0.21 for the premonsoon, monsoon and post-monsoon seasons, respectively, and for pressure networks, 0.5 - for all three seasons. It is important to note that pressure correlations over the Indian subcontinent are much higher than temperature correlations (see Table 3). The longer time period of the APHRODITE data set allows us to infer statistically significant correlations of the extreme rainfall synchronization in the long term, and similarities between the APHRODITE and TRMM data sets show the permanent pattern of the extreme rainfall synchronization

In this study, we use gridded data sets to construct networks of extreme precipitation, temperature and pressure fields. It is important to note, however, that climate networks derived from gridded data sets are affected by the spatial sampling of these data. Specifically, spatial sampling has an effect on network measures. This important issue is discussed in Molkenthin et al. (2014), where the effect of spatial sampling on the network measures is illustrated on the ISM climate network derived from NCEP/NCAR daily temperature anomalies using the method discussed in Sect. 2.2.2. This study has shown that spatial sampling of 
Table 3. Details of network construction and thresholding. Extreme rainfall event networks: the average number of events per grid point during the considered period (MAM, JJAS, or OND), the mean number of synchronized events, and the maximal number of synchronized events. Temperature and pressure networks: thresholds of the Pearson correlation for the MAM, JJAS, and OND periods.

\begin{tabular}{|c|c|c|c|}
\hline Data & MAM & JJAS & OND \\
\hline \multicolumn{4}{|l|}{ TRMM } \\
\hline Avg. number of events & 126 & 175 & 120 \\
\hline Avg. number of synchronized events & 21 & 34 & 24 \\
\hline Max. number of synchronized events & 114 & 162 & 111 \\
\hline \multicolumn{4}{|c|}{ APHRODITE } \\
\hline Avg. number of events & 517 & 693 & 517 \\
\hline Avg. number of synchronized events & 104 & 132 & 107 \\
\hline Max. number of synchronized events & 489 & 655 & 486 \\
\hline \multicolumn{4}{|c|}{ NCEP/NCAR: thresholds } \\
\hline Temperature & 0.19 & 0.15 & 0.21 \\
\hline Pressure & 0.5 & 0.5 & 0.5 \\
\hline
\end{tabular}

gridded NCEP/NCAR data does not qualitatively change network measures for the Indian region.

\subsubsection{Network measures}

In this study, we compare networks of the pre-monsoon, monsoon and post-monsoon periods using four network measures: degree, betweenness, average link length and maximal link length. Analytical definitions of the network measures are presented in Table 2.

The degree of a node (i.e., the geographical site) $i$ in the network gives the number of links connected to node $i$.

The shortest path between two nodes is the way to go from one node in the network to another using a minimal number of links. For given nodes $i$ and $j$ in the network, $\sigma(i, j)$ shortest paths exist. If a large fraction of the shortest paths from a node $i$ to a node $j$ pass through a certain node $v, v \neq i, j$, then node $v$ is an important mediator for transport through the network, and we would consider this node to have a high betweenness. In this study, extreme rainfall event transport is related to the propagation of the extreme rainfall over the subcontinent. Note: the interpretation of betweenness in this study is that it indicates the extreme event pathways through the network of extreme rainfall. As a result, patterns with high betweenness can play a crucial role in understanding the mechanism of extreme event transport over the Indian subcontinent (see Sect. 3).

The average geographical link length $A L L_{i}$ (maximal geographical link length $M L L_{i}$ ) of a node $i$ is the average (maximum) geographical distance of that node's links.

\section{Results}

First, we determine general features that correspond to the chosen time period, the so-called "dominant" patterns of the entire time period, by comparing climate networks for the pre-monsoon, ISM and post-monsoon periods using the TRMM data. Second, we present a visualization of the links of the dominant patterns of ISM during the three seasons, and analyze the seasonal evolution of these patterns. In order to understand which atmospheric processes cause synchronization of extreme rainfall events, we compare the visualization of links of these patterns with wind fields. Third, we compare the results of the network analysis for the APHRODITE and TRMM data sets. Finally, we build networks from the temperature and pressure fields over the Indian peninsula for three seasons, and compare the structure of these networks with dominant patterns of the ISM extreme rainfall.

\subsection{TRMM}

\subsubsection{Network measures}

Figure 3 shows the degree, betweenness and the average geographical link length of the networks for the TRMM data (see Tables 1 and 2).

- Degree: during the pre-monsoon period, there are five regions with a high degree: (i) Western Ghats (WG) and the Arabian Sea, (ii) North Pakistan (NP), (iii) the Himalaya, (iv) Eastern Ghats (EG) and the Bay of Bengal, and (v) the Tibetan Plateau (TP). The regions (i) and (iii) have an especially high degree during the pre-monsoon season. During the monsoon season, the highest degree is in NP, EG and TP, while during the post-monsoon season, it is in the Himalaya, TP and NP.

- Betweenness: high betweenness is observed for the premonsoon, monsoon and post-monsoon seasons for the same regions, as specified above with a high degree.

- Average and maximal geographical link lengths: comparatively long links can be found in the Arabian Sea and the Bay of Bengal during the pre-monsoon period; in NP, TP, EG and the Himalaya during the monsoon season; and in TP and the Himalaya during the postmonsoon period.

Examining the distributions of the link lengths of the TRMM data yields some interesting behavior (see Fig. 4). There are two peaks in the distributions of the average link length of the pre- and post-monsoon seasons, at about $250 \mathrm{~km} / 450 \mathrm{~km}$ and $300 \mathrm{~km} / 800 \mathrm{~km}$, respectively, while the monsoon season has a pronounced single peak, at around $450 \mathrm{~km}$. More specifically, the maximum of the average link length distribution shifts from $250 \mathrm{~km}$ up to $450 \mathrm{~km}$ and back down to $300 \mathrm{~km}$ between the three seasons. We also calculate the average link length over the whole region, and find a 

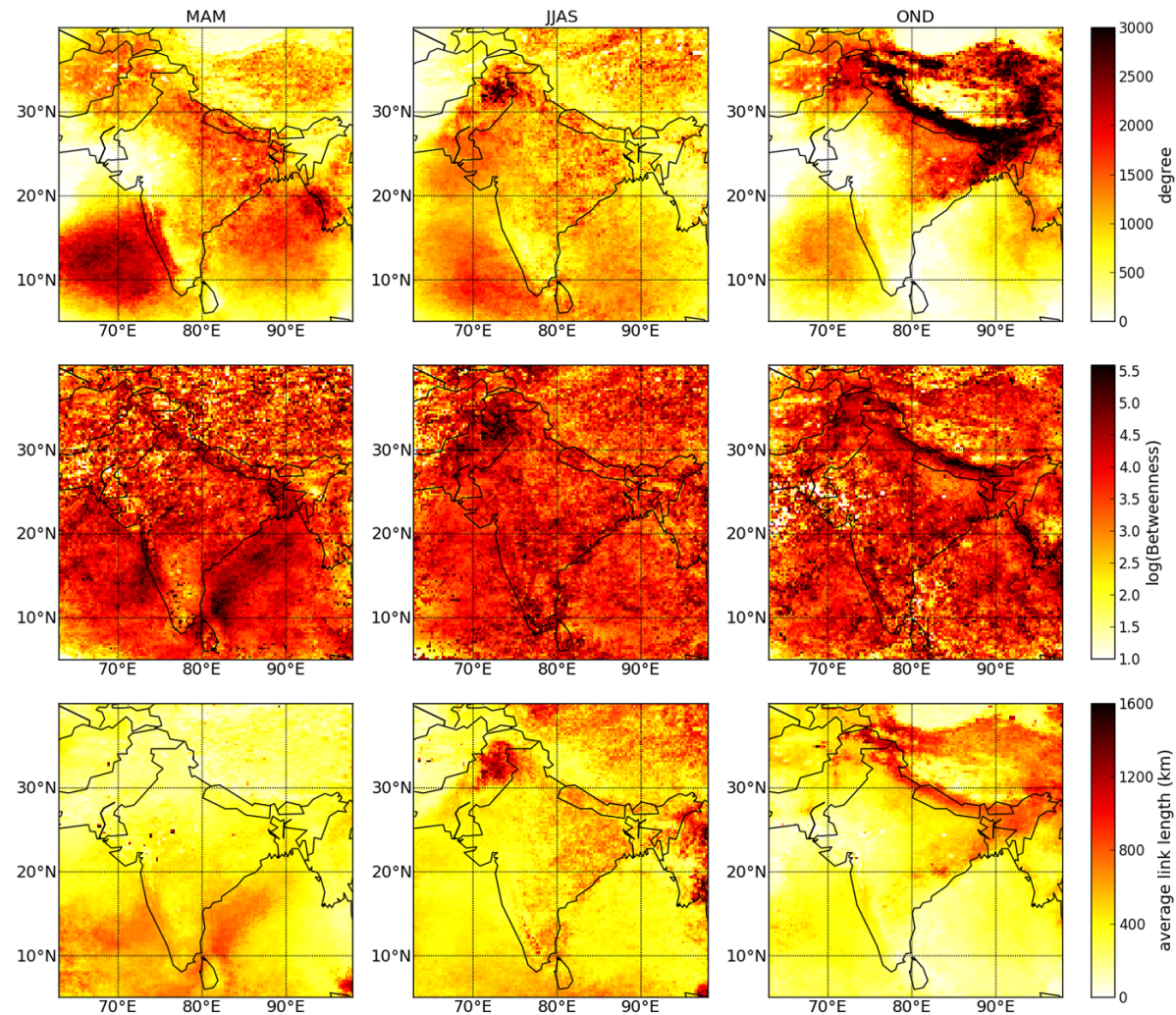

Figure 3. Common network measurements for the three time periods based on the TRMM data: pre-monsoon (MAM), monsoon (JJAS), and post-monsoon (OND). From top to bottom: degree, betweenness, average geographical link lengths.
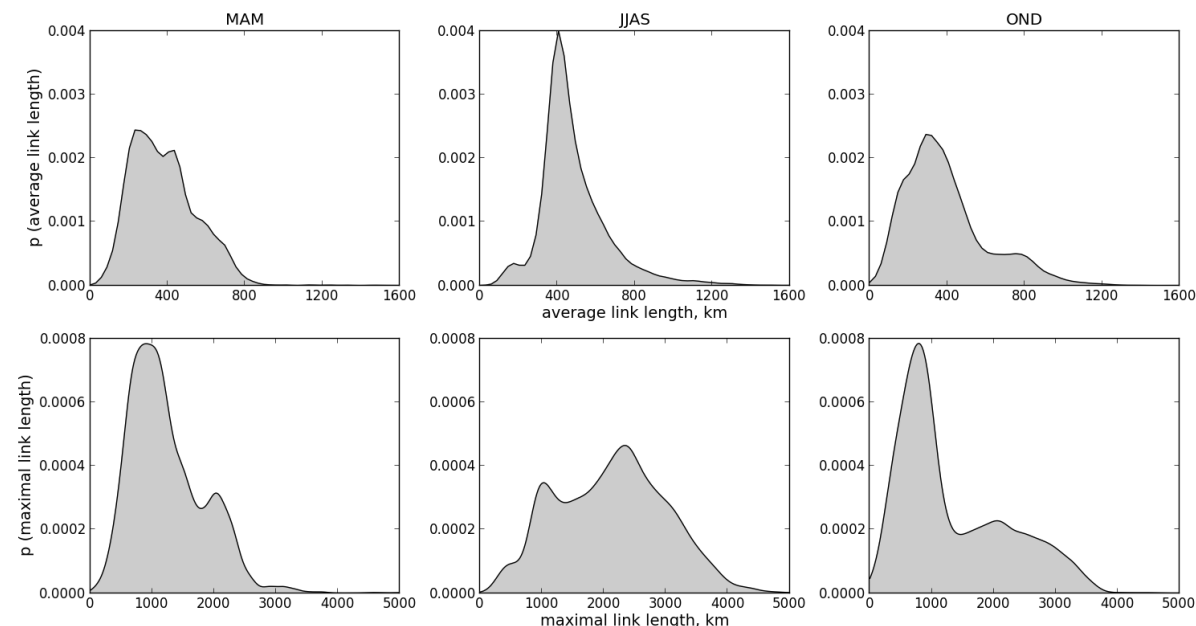

Figure 4. Average and maximal link length distributions for the three time periods based on the TRMM data: pre-monsoon (MAM), monsoon (JJAS), and post-monsoon (OND).

distance of $484 \mathrm{~km}$ for the monsoon season, compared to the shorter 382 and $390 \mathrm{~km}$ for the periods before and after the monsoon, exemplifying a trend toward longer links during the monsoon period. It is also worth noting the long tail of the monsoon season distribution, when compared with those of the pre- and post-monsoon seasons. The maximal link length distributions are also shown in Fig. 4, and are bimodal in all three seasons.

Employing the network measures outlined above, we look into the role of hubs (super nodes) in the organization of the spatial structure of the pre-monsoon, monsoon, and postmonsoon periods. We define the hubs of a network as the 
Table 4. Hubs of the extreme rainfall networks. Columns are hubs in degree, betweenness, and average link length. "+" - the network measure in the given region is in the top $10 \%$ for the given period. "-_- lower than the top $10 \%$. The order of "+" or "-" means the season: pre-monsoon, monsoon, and post-monsoon, respectively. For example, the intersection of first row and first column (North Pakistan (NP) and degree) - " $+/+/+"$ - means that one can observe a high degree in NP during the pre-monsoon, monsoon, and post-monsoon seasons, respectively.

\begin{tabular}{|c|c|c|c|}
\hline & $\begin{array}{l}\text { Degree, } \\
D_{i}\end{array}$ & $\begin{array}{l}\text { Betweenness, } \\
B_{v}\end{array}$ & $\begin{array}{l}\text { Average } \\
\text { geographical } \\
\text { link length, } \\
\mathrm{ALL}_{i}\end{array}$ \\
\hline North Pakistan, NP & $+/+/+$ & $-1+1-$ & $-1+1-$ \\
\hline Tibetan Plateau, TP & $+/+/+$ & $-1-1-$ & $-/+1+$ \\
\hline Eastern Ghats, EG & $+/+/+$ & $-1+1-$ & $-/+1-$ \\
\hline Himalaya & $+/-1+$ & $+/-1+$ & $-/+1+$ \\
\hline Western Ghats, WG & $+1-1-$ & $+1-1-$ & $+1-1-$ \\
\hline Arabian Sea & $+1-1-$ & $+1-1-$ & $+1-1-$ \\
\hline Bay of Bengal & $+1-1-$ & $+1-1-$ & $+1-1-$ \\
\hline
\end{tabular}

$10 \%$ of grid points with the highest degree, betweenness, and average link length. We infer seven main patterns that have either a high degree, betweenness, or average link length during at least one of the three time periods (see Table 4). Three of these patterns are believed to be dominant during the ISM. First, the NP region shows a high degree, betweenness, and average link length during the monsoon season, indicating a large number of long connections in this region during this time. The high betweenness of the NP region shows its importance in the synchronization of extreme rainfall events over the Indian subcontinent specifically during the monsoon period. The EG and TP regions also have a large number of long connections during the monsoon season, with TP showing a similarly large number in the post-monsoon season as well. These regions, therefore, play an important role in the organization of the structure of extreme rainfall event synchronization, primarily during the monsoon season. Using a similar analysis for the other time periods, we uncover the main patterns in the networks of extreme rainfall event synchronization for each season: (i) pre-monsoon season: WG, the Himalaya - over the land, and the Arabian Sea and the Bay of Bengal; (ii) monsoon: NP, EG and TP; (iii) postmonsoon: the Himalaya and TP.

We find three dominant patterns for the ISM season: NP, EG and TP. These patterns are characterized by a high degree, high betweenness (except for TP), and the longest average geographical link lengths during this season. They are specific signatures of the ISM, which start to form in the pre-monsoon season, and disappear during the post-monsoon season. Therefore, these regions deserve special attention for understanding the spatial structures of the synchronization of extreme rainfall events during the monsoon season, and we highlight them in the analysis that follows. In the next section, we focus on the links of the dominant patterns of ISM, and compare their changes during the three seasons.

\subsubsection{Link visualization}

In the previous section, dominant patterns for the ISM were described: NP, TP and EG. This section focuses on the seasonal evolution of these patterns and their connections with other areas on the Indian subcontinent. From each of these patterns, we choose 153 nodes, and extract and integrate all links that belong to these patterns. This so-called "link visualization" is shown in Fig. 5.

Links stemming from the NP pattern show local synchronization of extreme rainfall events during the pre-monsoon season. This phenomenon is not surprising, given the mountainous terrain of the region. During the ISM, however, longrange connections appear; extreme rainfall events in the NP region synchronize with events in TP, the Himalaya, EG and Burma (Fig. 5). These clusters are of great interest for further research, as they appear only during the ISM season, and are possibly linked to monsoonal trends in wind strength (see Sect. 3.3). The post-monsoon season sees a decrease in the number of connections to points in the NP region, but maintains connections to TP and the Himalaya.

The TP pattern also shows local synchronization of extreme rainfall events during the pre-monsoon season. Once again, this coincides with the topography of the region that prevents rainfall from synchronizing with other regions. However, the TP has many links to both the NP and EG regions during the ISM. These connections are long range and, possibly, caused by large-scale atmospheric processes such as ISM winds and Western Disturbances. During the postmonsoon season, the connections are more locally clustered within the TP, and there are also a lot of connections between $\mathrm{TP}$ and the Himalaya.

The EG pattern shows the most intricate behavior of extreme rainfall event synchronization: the shape of the pattern varies noticeably from season to season. During the premonsoon season, extreme rainfall events are synchronized within the EG region, and with the WG region and the Arabian Sea. During the ISM, there are three main clusters of synchronized extreme rainfall that are connected to the EG region: NP, TP and WG. During the post-monsoon season, the synchronization resembles that of the pre-monsoon season (see Fig. 5), with additional connections to the Himalaya. This feature has a climatological interpretation, since the Himalaya receive heavy rainfall during the post-monsoon season.

\subsection{TRMM vs. APHRODITE}

\subsubsection{Network measures}

In this section, we compare 15-year satellite-derived TRMM data with 57-year reanalysis APHRODITE data 

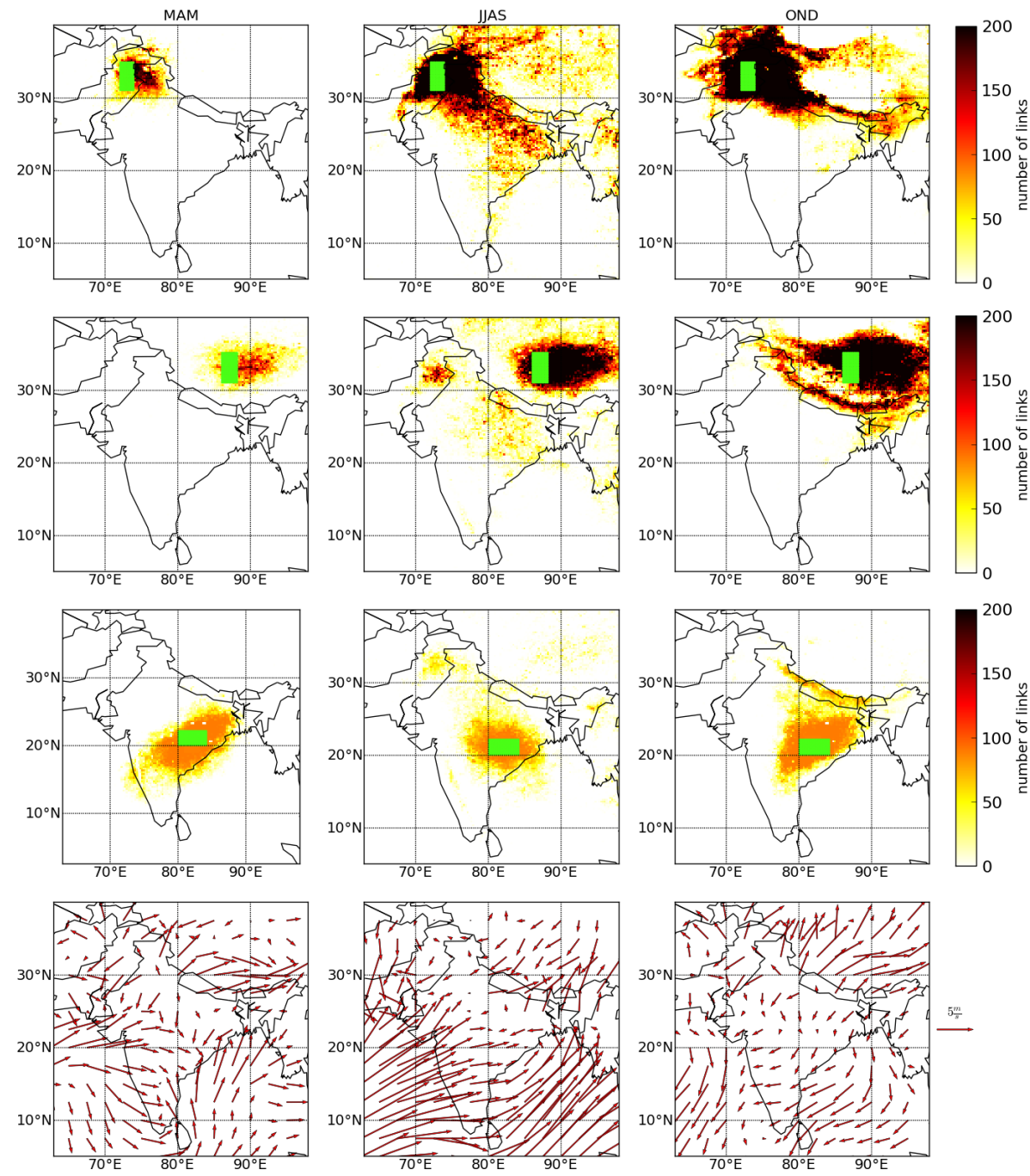

Figure 5. Links between a set of 153 reference grid points and other grid points, and the surface wind vector mean between 1998 and 2012. From top to bottom: North Pakistan (NP), Tibetan Plateau (TP), Eastern Ghats (EG) (TRMM) and the surface wind vector mean (NCEP/NCAR).

using networks of extreme rainfall (see Table 1). The reason for comparison of these two data sets is discussed in Sect. 2.1. Figure 6 shows the degree, betweenness and the average geographical length of the networks for the APHRODITE data (see Tables 1 and 2). We find that geographic patterns of networks derived from the APHRODITE data show strong differences in comparison to the TRMM data.

- Degree: during the pre-monsoon season, areas in WG and Burma have a low degree according to the APHRODITE data set, and a high degree for the TRMM data set. The EG region, marked by a high degree for TRMM during the monsoon season, shows a low degree for APHRODITE. The post-monsoon season also has some discrepancy, with low and high degree in the NP pattern for the APHRODITE and TRMM data sets, respectively. There are, however, some similarities as well, such as the existence of hubs in NP, TP and the Himalaya for pre-monsoon, NP and TP for monsoon, and the Himalaya for post-monsoon.

- Betweenness: the betweenness hub for APHRODITE during the pre-monsoon period is in the Himalaya. This corresponds to the highest rainfall over the Himalaya during the pre-monsoon season and the beginning of the monsoon formation over WG, EG and Burma (see Fig. 2). During the ISM, TRMM finds that the areas with high betweenness are in NP and EG, while in the post-monsoon season, the high betweenness shifts to the Himalaya and WG. In all three seasons, the TRMM data set agrees with the APHRODITE data set as far as identifying areas of high betweenness goes (see Figs. 3 and 6). The lack of APHRODITE data over the ocean 

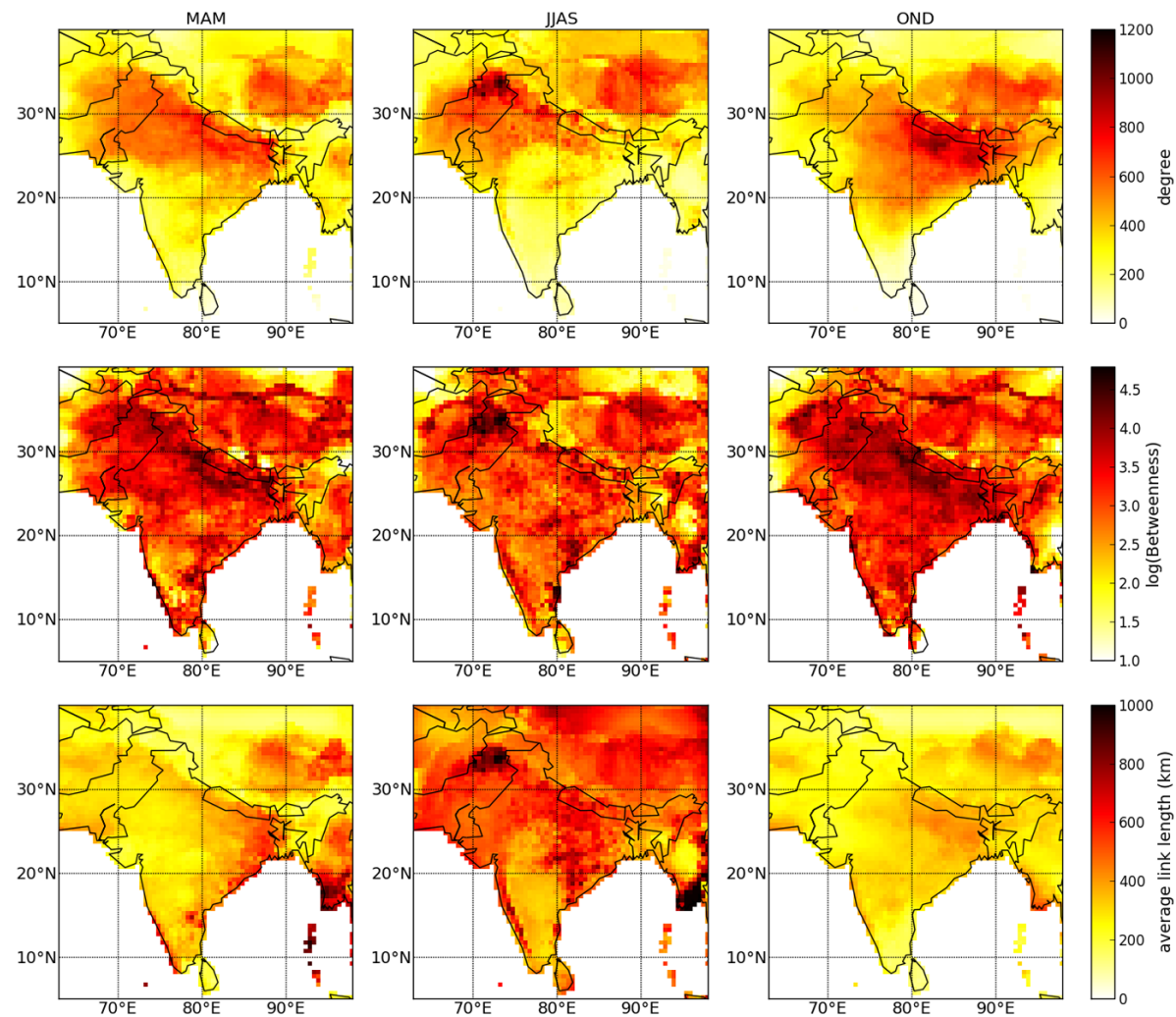

Figure 6. Common network measurements for the three time periods based on the APHRODITE data: pre-monsoon (MAM), monsoon (JJAS), and post-monsoon (OND). From top to bottom: degree, betweenness, average geographical link lengths.

does not affect the betweenness of the network, besides coastal areas.

- Average geographical link length: the longest links during the pre-monsoon season for the TRMM data can be found in the Arabian Sea and the Bay of Bengal, but in TP and EG for the APHRODITE data. During the ISM, the APHRODITE data show new patterns that appear in NP and Burma, while the pattern in WG disappears. The post-monsoon season sees a shift in the longest link lengths, and reveals three main patterns: the eastern $\mathrm{Hi}-$ malaya, TP and Burma, the first two of which coincide with the TRMM data.

It is important to note that similarities in the spatial patterns obtained from $0.25^{\circ}$ resolution TRMM data with patterns obtained from $0.5^{\circ}$ resolution APHRODITE data allow us to conclude that the obtained patterns are reliable, and do not depend on the resolution of the data.

\subsubsection{Link visualization}

In this section, we compare the seasonal evolution of the connections of patterns for the APHRODITE and TRMM data sets. Similarly to Sect. 3.1.2, we choose 45 points from the APHRODITE data set and obtain Fig. 7, which is an analog to Fig. 5 for the TRMM data.
Connections to the NP region do not qualitatively change from season to season for APHRODITE, unlike for TRMM. The NP pattern from the APHRODITE data set has a larger region of synchronized rainfall during all three seasons (see Figs. 5 and 7). The pre-monsoon season shows many links between NP and the eastern Himalaya for APHRODITE, but not for TRMM. During the monsoon season, there are no long-range connections to TP in APHRODITE, as there are in TRMM. For the post-monsoon season, the connections are clustered locally, unlike the TRMM pattern, which also includes links to the Himalaya.

The TP region in APHRODITE shows a different spatial distribution of links than in the TRMM data (see Figs. 5 and 7). The APHRODITE TP region does not show strong seasonal changes in the connections. The pre-monsoon season reveals connections to the eastern Himalaya, and the ISM shows no synchronization of extreme rainfall with NP, both of which are contrary to the TRMM data. Moreover, during the post-monsoon period, the APHRODITE data set displays a wider range of connections than the TRMM data do.

The EG pattern from the APHRODITE data also differs from the pattern obtained from the TRMM data. In the premonsoon season, connections extend to the Himalaya for APHRODITE, but not for TRMM. The ISM season uncovers two main clusters - NP and Burma - where extreme rainfall is 

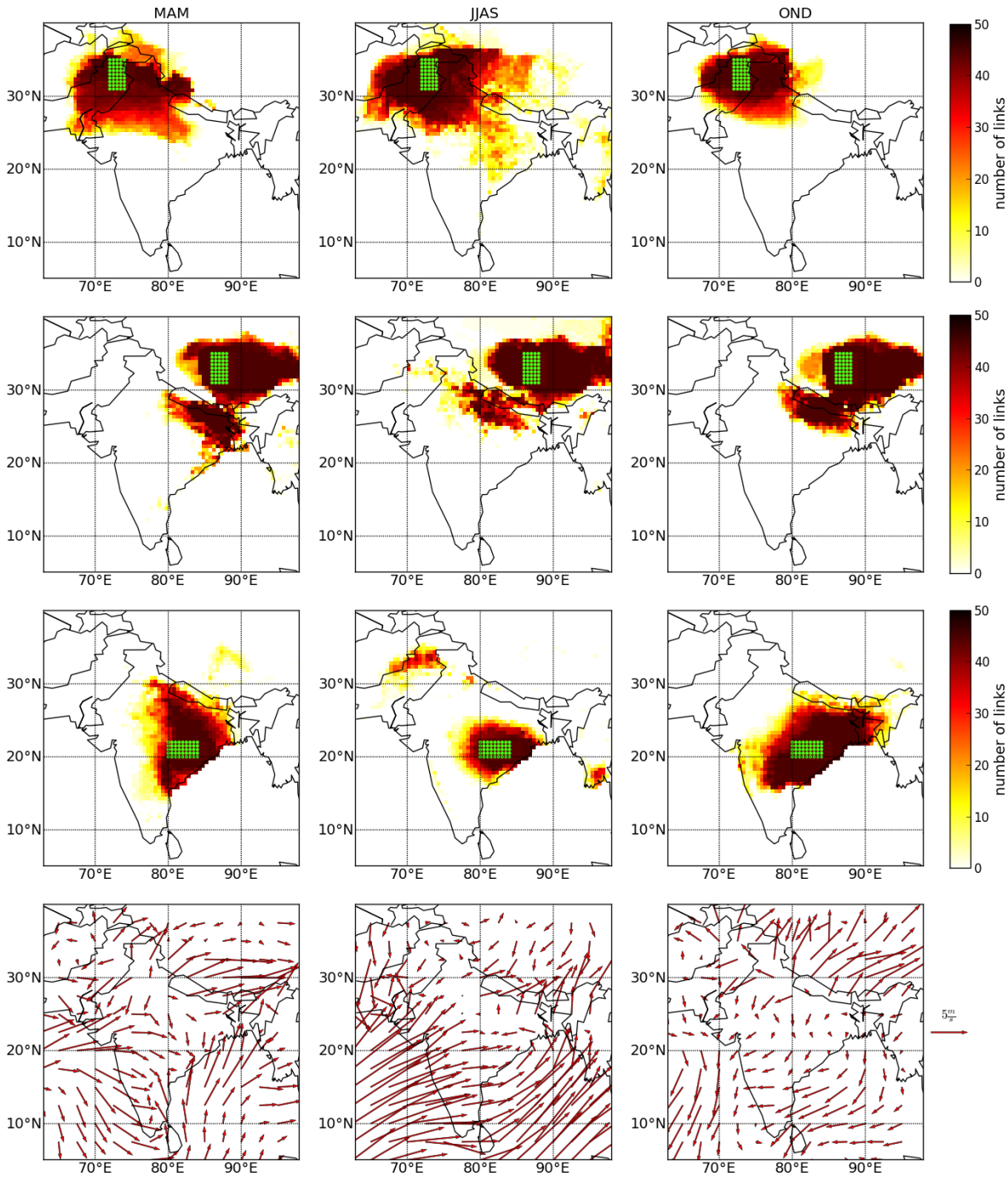

Figure 7. Links between a set of 45 reference grid points and other grid points and the surface wind vector mean between 1951 and 2007. From top to bottom: North Pakistan (NP), Tibetan Plateau (TP), Eastern Ghats (EG) and the surface wind vector mean (NCEP/NCAR data).

synchronized with the EG region, while the TRMM data set has additional links to WG and TP. Also, there is no synchronization of extreme rainfall events in the area between the NP and EG regions from both the APHRODITE and TRMM data. During the post-monsoon season, events are synchronized locally, and not with the Himalaya, unlike the pattern derived from TRMM (see Figs. 5 and 7).

\subsection{Comparison of network structures of TRMM and APHRODITE with surface vector mean wind fields}

Here, we compare the mean surface wind fields for the three time periods - pre-monsoon, ISM and post-monsoon - with the patterns obtained previously from the network analysis (see Sects. 3.1.1 and 3.2.1, Figs. 5 and 7).

The directionality of the winds over the Indian subcontinent partially explains the synchronization of extreme rainfall events within the patterns in NP and TP during the pre- and post-monsoon periods. These patterns follow the topography that prevents the rainfall from synchronizing with other locations across the subcontinent: NP is a low-elevation area, bounded by mountains in the northwest, north and northeast directions; TP is a high-elevation plateau, bounded by the Himalaya in the southwest. The TRMM data show a strong resemblance to the changing winds across the three seasons (see Fig. 5), while the APHRODITE data show no significant changes (see Fig. 7).

The shape of the APHRODITE EG region during the preand post-monsoon seasons, however, matches the wind direction, whereas the TRMM data in the same region cannot be explained fully from the wind field. During the premonsoon season, the APHRODITE data set shows a spread from south to north, following the winds. The post-monsoon pattern also corresponds to the wind direction: from northeast 

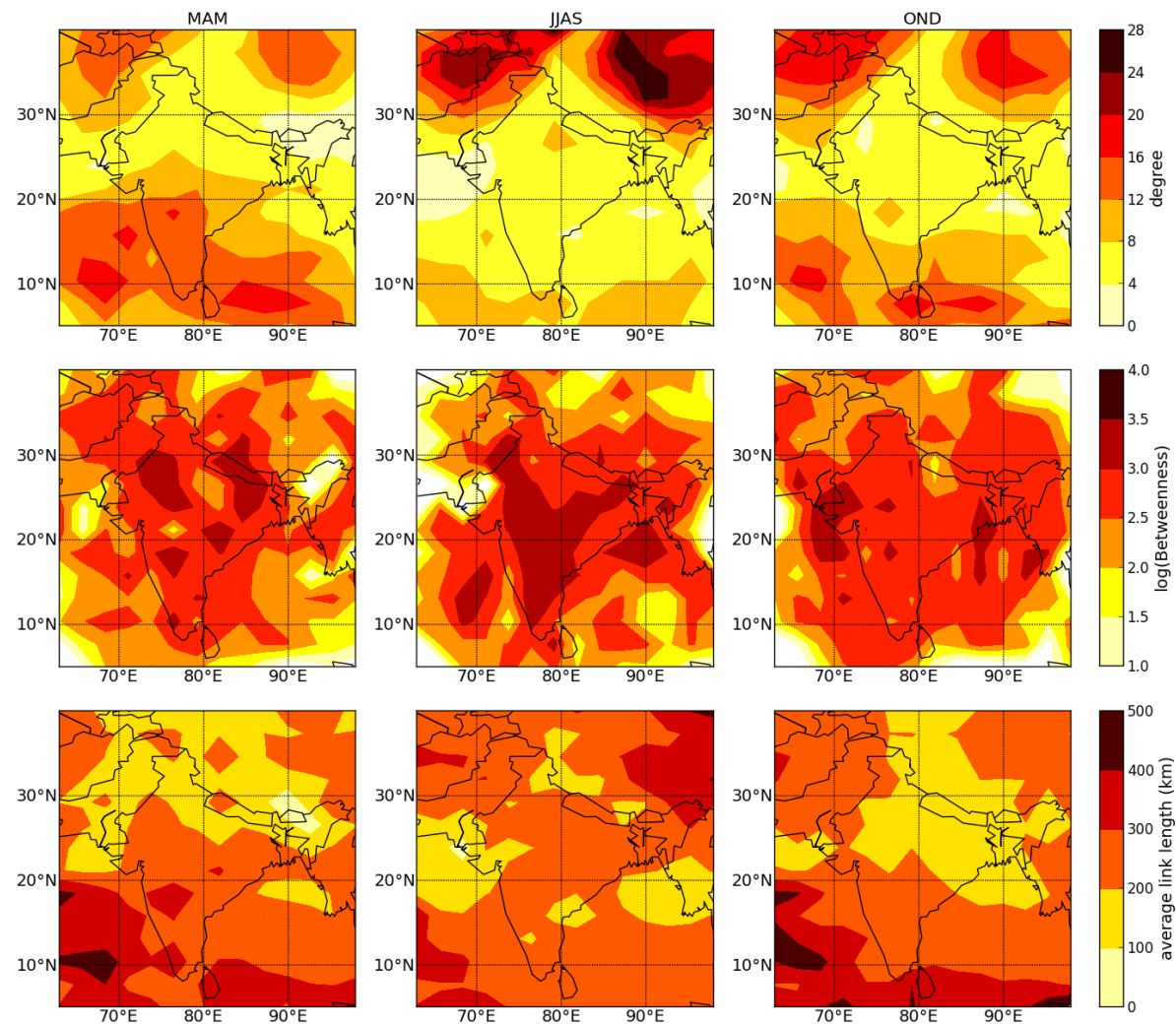

Figure 8. Common network measurements for the three time periods based on the NCEP/NCAR data for the pre-monsoon (MAM), monsoon (JJAS), and post-monsoon (OND) temperature networks. From top to bottom: degree, betweenness, average geographical link lengths.

to southwest. The noteworthy observation is that during the pre-monsoon season, the spatial pattern in NP coincides with the divergence of the surface vector mean winds, while the EG spatial pattern coincides with the convergence of surface vector mean winds for both the APHRODITE and TRMM data. During the monsoon season, surface vector mean winds change dramatically, and the NP spatial pattern coincides with wind convergence, while during the post-monsoon season, the NP spatial pattern coincides with wind divergence.

The ISM season shows a difference between rainfall event synchronization and wind fields, in both data sets. As mentioned above, there are connections between NP and EG, but not in the area between these two regions. This seems to indicate that winds are not the cause of this synchronization. However, this phenomenon may be caused by the topography of these regions and the influence of two branches of the ISM: the Bay of Bengal branch that transports moisture and interacts with the wind systems from the Arabian Sea branch.

\subsection{Comparison of patterns of extreme precipitation with patterns obtained from temperature and pressure fields}

In this section, we analyze the seasonal evolution of climate networks over the Indian subcontinent. We compare networks of extreme rainfall (analyzed in previous sections) with networks of temperature and pressure fields (see Figs. 8 and 9).

- Temperature network: degree: a temperature network obtained from the NCEP/NCAR data (see Sect. 2.1, Table 1) for the pre-monsoon season exhibits degree hubs in NP/Afghanistan, TP and the southern part of the Indian peninsula, including Sri Lanka (see Fig. 8). During the ISM season, only two of the previously identified patterns appear - NP/Afghanistan and TP. The post-monsoon season has the same hubs as during the pre-monsoon season.

- Temperature network: betweenness: betweenness hubs of the temperature networks do not show a distinctive structure. They appear to be located in central India, and do not change qualitatively throughout the three seasons.

- Temperature network: average link length: during the pre-monsoon period, average link length hubs appear in the southern parts of the Indian peninsula, the Bay of Bengal and the Arabian Sea. The ISM hubs appear in NP/Afghanistan, TP, and in the southern Arabian Sea. As with degree, the post-monsoon season hubs match those of the pre-monsoon season. 

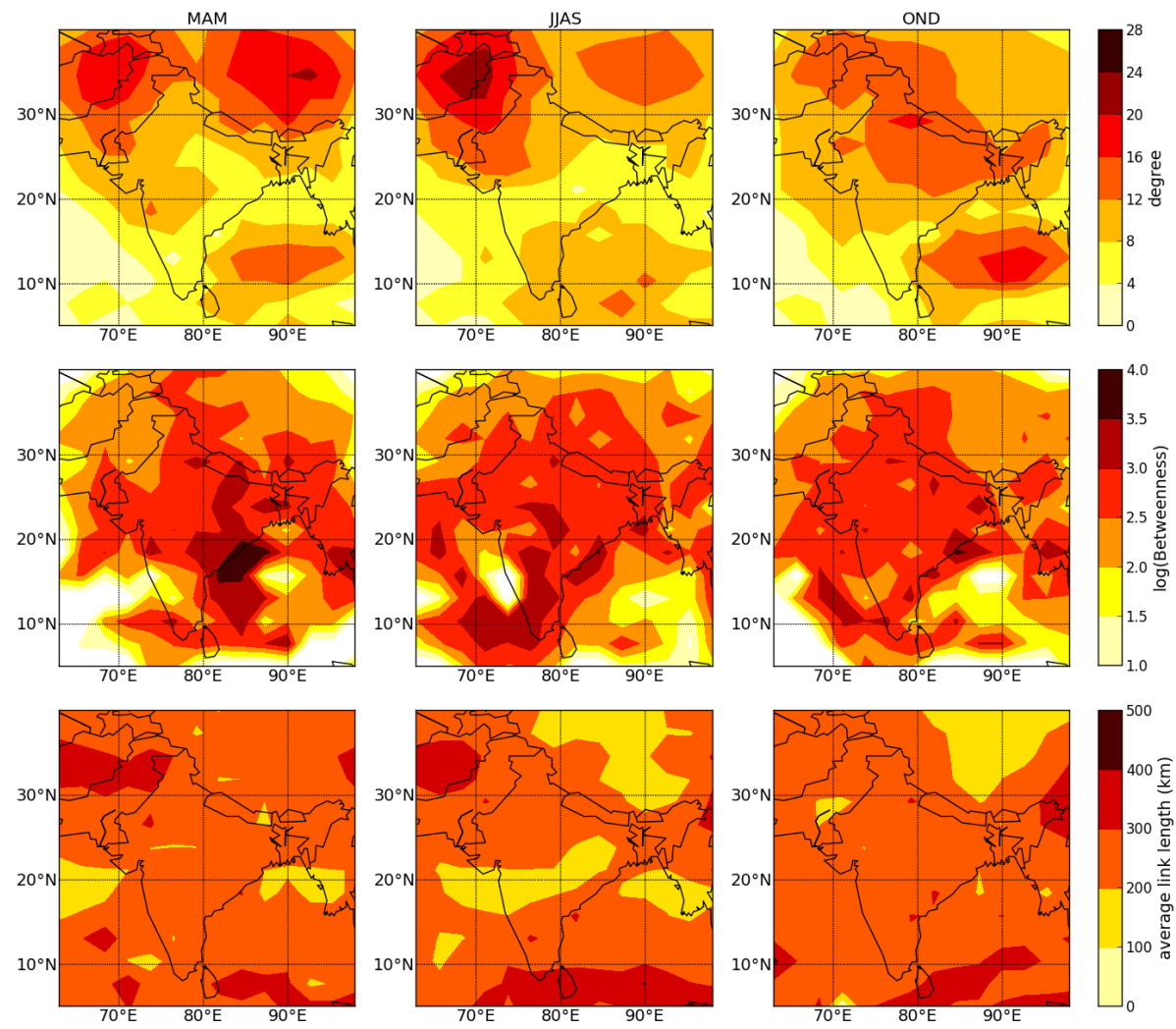

Figure 9. Network measurements for the three time periods: pre-monsoon (MAM), monsoon (JJAS), and post-monsoon (OND) pressure networks. From top to bottom: degree, betweenness, average geographical link lengths (NCEP/NCAR data).

- Temperature network vs. extreme rainfall network: during the pre-monsoon season, coincidence of the degree and the average link length hub of the temperature network with the WG and Arabian Sea hub of the extreme rainfall network (high degree, betweenness and the average link length) emphasizes the role of the Arabian Sea in controlling extreme rainfall over the western coast of the Indian subcontinent. During the ISM, the NP and TP hubs of the temperature network coincide with hubs of the extreme rainfall network, and the long average link length of the TP in the temperature network points out the importance of the TP in the distribution of the temperature gradient over the Indian subcontinent, which creates a pressure gradient and affects the distribution of the extreme rainfall through wind systems. During the post-monsoon season, the effect of the NP and TP hubs on the temperature and extreme rainfall synchronization networks weakens. While temperature changes during the post-monsoon season are governed mostly by the surface air temperature of the Arabian Sea and the Bay of Bengal (see Fig. 8), extreme rainfall synchronization during this season is controlled by TP and the Himalaya (see Figs. 3 and 5). For consideration of the important issue of annual and decadal evolution of the temperature networks over the Indian subcontinent, we refer the reader to Tupikina et al. (2014).

- Pressure network: degree: the pressure network constructed based on data from NCEP/NCAR shows premonsoon degree hubs in the regions of NP, Afghanistan, TP, the Bay of Bengal and Sri Lanka (see Fig. 9). These hubs maintain their locations during the ISM season and, additionally, the Bay of Bengal hub extends across the southern tip of India. During the post-monsoon season, the hubs combine to form one large hub over the central and northern parts of India and the Bay of Bengal.

- Pressure network: betweenness: the betweenness does not show well-defined patterns across all seasons, except for the EG hub during the pre-monsoon season. Difficulties in the pattern determination on the betweenness maps may be due to the relatively small number of nodes in this network.

- Pressure network: average link length: the hubs of the average link length, although not very distinguished, are still observable in NP, Afghanistan and along the $5-10^{\circ} \mathrm{N}$ belt over Sri Lanka. They appear during the pre-monsoon season, do not change across the ISM, and 
cover the whole region, except for TP during the postmonsoon season.

- Pressure network vs. extreme rainfall network: during the pre-monsoon season, NP, TP and Bay of Bengal spatial patterns of the pressure network coincide with the spatial patterns of the extreme rainfall network. During the monsoon season, low pressure over TP affects extreme rainfall locally on the plateau, and over the Himalaya. The NP hub in the pressure network during the pre-monsoon and monsoon seasons most likely affects extreme rainfall over the Indian subcontinent through the influence of Western Disturbances, which intensify the monsoon activity over the northern part of the Indian subcontinent. During the post-monsoon season, however, hubs of the extreme rainfall network are much more localized over the Himalaya, while pressure network hubs extend over the Indian subcontinent and the Bay of Bengal. This feature could be explained either by the low resolution of the pressure data, or by higher frequency variability of the extreme rainfall.

Comparison of the hubs of temperature and pressure networks with dominant patterns of the network of extreme precipitation over the Indian peninsula and Sri Lanka shows that the NP and TP regions can be characterized as dominant patterns (hubs) of the ISM and post-monsoon temperature network, while the regions of EG and WG are more closely linked to the pre-monsoon season. On the other hand, NP and TP are dominant patterns of the pre-monsoon and ISM pressure network.

\section{Discussion}

In this study, we compare the spatial structures of synchronized extreme rainfall events for the rain-gauge interpolated (APHRODITE) data set (Yatagai et al., 2009), which was used in previous studies (Malik et al., 2010, 2011), with recent satellite-derived Tropical Rainfall Measurement Mission (TRMM) data set (Huffman et al., 2007; Bookhagen and Burbank, 2010) that covers a larger spatial domain, including the Indian Ocean. We have shown that there are many similarities regarding the synchronization of extreme rainfall events between these two data sets over the land (see Sects. 3.2.1 and 3.2.2). Taking into account the longer time period of the APHRODITE data set, we argue that patterns obtained for TRMM that coincide with patterns from APHRODITE are robust for the time period from 1951 to 2012. However, there are differences between the two data sets as well, namely the high-degree TRMM patterns in WG and Burma, which are not reflected in the APHRODITE data. The fact that these differences are in coastal areas allows us to assume that they are caused by a lack of APHRODITE data over the oceans, especially since the high-degree behavior comes primarily from connections to the surrounding bodies of water.

Based on our complex network analysis, we have revealed three dominant spatial patterns in the network of extreme precipitation during the ISM (Sect. 3.1): North Pakistan (NP), Eastern Ghats (EG), and the Tibetan Plateau (TP); and two main spatial patterns for the pre- and post-monsoon seasons: Western Ghats (WG) and the Himalaya. All of these patterns coincide with the topography of the Indian peninsula, and four of them - EG, WG, TP, and the Himalaya - play a governing role in the onset and spatial organization of the ISM extreme rainfall (Wang, 2006; Pai and Nair, 2009; Malik et al., 2010, 2011). However, we show that the NP pattern also strongly influences the network of extreme rainfall over the Indian subcontinent, and should be taken into account when studying the ISM dynamics.

The EG, WG, TP and Himalaya patterns are known as areas that influence the ISM dynamics, mostly because of the intricate topography of these regions that forces orographic lifting and high rainfall amounts. The Western Ghats are the first highlands of the Indian subcontinent encountered by the ISM winds. The mountains rise abruptly from the western coastal plains of the subcontinent, creating an orographic barrier for the monsoonal winds. The $\mathrm{WG}$, together with the Himalaya, is the main cause of the substantial orographic precipitation all across the Indian subcontinent during the ISM season (Bookhagen and Burbank, 2010). During the winter season, however, it is the Eastern Ghats that create an orographic barrier for the rainfall during the post-monsoon season. The Tibetan Plateau is another important region during the winter months, as precipitation in the region is caused by winter westerlies. It was shown that persistent warming on the Tibetan Plateau for the last three centuries coincides with intensification of the ISM, and the cool/warm epochs in TP also coincide with a weak/strong ISM (Feng, 2005). Our results from temperature, pressure, and extreme precipitation networks confirm the important role of the above-mentioned regions in the ISM dynamics.

The formation of the NP pattern during the ISM is caused by the topography of the region that, together with the ITCZ and the Arabian Sea branch of the ISM, promotes the formation of wind convergence in this region. This can explain why the NP region is characterized by both high degree and high betweenness: the convergence of surface winds is caused by the low pressure in the NP area. The high degree, betweenness, and average link length that we have observed in NP supports the theory that it is not the differential heating of the land and sea that is the governing mechanism of the ISM, but the monsoonal winds along with the Himalaya that act as a high shield that stops Siberian dry and cold air from penetrating the Indian subcontinent (Webster, 1998; Chakraborty, 2002; Sinha et al., 2013; Boos and Kuang, 2010). Additionally, rainfall in the NP region is mostly caused not by the monsoonal rainfall, but by Western Disturbances, which transport moisture from the Caspian Sea to the low-pressure 
area of the NP. In this study, we have shown that the NP region influences extreme rainfall synchronization across a large area of the Indian subcontinent. We suggest that since this region reflects Western Disturbances and influences extreme rainfall over most of the Indian subcontinent, it can serve as an indicator region for the interaction between the ISM system and Western Disturbances. Therefore, it might deserve careful consideration as one of the key regions, along with the EG (because of their connection), for the analysis of the ISM interaction with Western Disturbances, as well as for the analysis of floods in Pakistan.

We also observe several common features in the networks of extreme precipitation, temperature and pressure fields during the three seasons, as well as unique features for each season. Common features of the networks of extreme precipitation are a high degree and betweenness over NP and EG during the ISM, and a high average link length in NP, EG, TP and the Himalaya also during the ISM, confirming their role in ISM dynamics. In particular, we find that the Himalaya play more than just the role of an orographic barrier, blocking ISM winds from blowing rainfall into China, Afghanistan, and Russia. For the temperature and pressure networks, the common features are a high degree over both NP and TP (see Table 4).

Each of the three considered seasons also has its unique features, such as different long-range directions of the extreme rainfall synchronization that coincide with the main winds during the chosen season, or the dominant role of the NP pattern during the ISM. Our results can be explained as follows: the common patterns in the networks for the three seasons are caused by permanent properties of the underlying system, such as topography and geography, while the evolution of these patterns is caused by seasonal factors and, in particular, monsoonal activity. Patterns of synchronization of extreme rainfall events during the ISM and post-monsoon seasons appear due to monsoonal southwesterly winds during the ISM and northeasterly winds during the post-monsoon season.

\section{Conclusions}

In this study, we have revealed the topology of extreme precipitation networks during the pre-monsoon, Indian Summer Monsoon, and post-monsoon seasons.

We have shown that the network of the Indian Summer Monsoon has three essential spatial domains: North Pakistan (NP), Eastern Ghats (EG), and the Tibetan Plateau (TP). These patterns are characterized by a high degree, high betweenness (except for TP), and the longest average geographical link lengths during this season. They start to form in the pre-monsoon season, and disappear during the post-monsoon season. The large number of connections and the long average link length of the NP, TP and EG regions during the ISM season imply that these regions strongly affect extreme rainfall event synchronization all over the Indian subcontinent. Also, the average and maximal link lengths of these regions are significantly increased in comparison to the premonsoon and post-monsoon periods.

The areas of the Eastern Ghats and the Tibetan Plateau were previously known as areas that influence the ISM dynamics due to the intricate topographies of these regions. We found that the NP pattern also plays an important role in the extreme rainfall organization during the ISM, because it is strongly influenced by Western Disturbances, and may serve as a key region for inferring interaction between the ISM system and Western Disturbances. It is important to note that, during the pre-monsoon season, the pattern in NP coincides with the area of divergence of the surface vector mean winds, while the EG pattern coincides with the convergence of the surface vector mean winds. During the ISM, this relationship between NP and EG patterns and winds reverses: NP coincides with wind convergence, while EG lies in the path of the Bay of Bengal monsoonal wind branch.

During the pre-monsoon season, the main patterns of the network of extreme rainfall event synchronization are Western Ghats and the Himalaya over the land, and the Arabian Sea and the Bay of Bengal. The Tibetan Plateau has the biggest influence on the network of extreme precipitation over the Indian peninsula and Sri Lanka during both the ISM and post-monsoon periods. We infer that the Tibetan Plateau pattern influences not only the ISM, but also pre-monsoon and post-monsoon dynamics. Also, it has been argued in the literature that this region influences the ISM rainfall dynamics (Feng, 2005; Wang, 2006; Rajagopalan and Molnar, 2013).

Therefore, the patterns detected in the NP, TP and EG regions are important for extreme rainfall synchronization during the ISM, while the patterns in WG and Himalaya mostly influence the synchronization of the extreme rainfall during the pre-monsoon season, and also, in the case of the $\mathrm{Hi}$ malaya, during the post-monsoon season.

We found that tracking the topology of networks of extreme rainfall events during the ISM and the periods before and after the monsoon might help to reveal the origins of the extreme rainfall events in the region. Currently, the Western Ghats pattern, or more specifically the Kerala region, is commonly used by climatologists for the prediction of the onset of the ISM (Pai and Nair, 2009). However, the observation of several patterns in several regions simultaneously could ultimately prove to be more effective for forecasting. We suggest that our findings be used for determining the timing and strength of the ISM by tracking the evolution of the dominant patterns described above.

Acknowledgements. The authors would like to acknowledge the support of the LINC project (no. 289447) funded by EC's Marie Curie ITN program (FP7-PEOPLE-2011-ITN), and the "Interactions and complex structures in the dynamics of changing climate" project funded by DFG. P. Martin would like to acknowledge the 
support of the National Science Foundation Graduate Research Fellowship Program. The authors thank Henk Dijkstra for helpful discussions, and Kira Rehfeld for visualization of topographical data. The authors would like to thank the two anonymous reviewers for their helpful comments. Complex-network measures have been calculated on the IBM iDataPlex cluster at the Potsdam Institute for Climate Impact Research using the pyunicorn software package.

Edited by: A. Loew

Reviewed by: two anonymous referees

\section{References}

Achuthavarier, D., Krishnamurthy, V., Kirtman, B. P., and Huang, B.: Role of the Indian Ocean in the ENSO-Indian Summer Monsoon Teleconnection in the NCEP Climate Forecast System, J. Climate, 25, 2490-2508, 2012.

Barreiro, M., Marti, A. C., and Masoller, C.: Inferring long memory processes in the climate network via ordinal pattern analysis, Chaos, 21, 013101, doi:10.1063/1.3545273, 2011.

Boers, N., Bookhagen, B., Marwan, N., Kurths, J., and Marengo, J.: Complex networks identify spatial patterns of extreme rainfall events of the South American Monsoon System, Geophys. Res. Lett., 40, 4386-4392, 2013.

Bookhagen, B. and Burbank, D. W.: Toward a complete Himalayan hydrological budget: Spatiotemporal distribution of snowmelt and rainfall and their impact on river discharge, J. Geophys. Res., 115, F03019, doi:10.1029/2009JF001426, 2010.

Boos, W. R. and Kuang, Z.: Dominant control of the South Asian monsoon by orographic insulation versus plateau heating, Nature, 463, 218-222, 2010.

Chakraborty, A.: Role of Asian and African orography in Indian summer monsoon, Geophys. Res. Lett., 29, 1989, doi:10.1029/2002GL015522, 2002.

Deza, J., Barreiro, M., and Masoller, C.: Inferring interdependencies in climate networks constructed at inter-annual, intra-season and longer time scales, Eur. Phys. J. Spec. Top., 222, 511-523, 2013.

Deza, J. I., Masoller, C., and Barreiro, M.: Distinguishing the effects of internal and forced atmospheric variability in climate networks, Nonlin. Processes Geophys., 21, 617-631, doi:10.5194/npg-21-617-2014, 2014.

Donges, J. F., Zou, Y., Marwan, N., and Kurths, J.: The backbone of the climate network, Europhys. Lett., 87, 48007, doi:10.1140/epjst/e2009-01098-2, 2009a.

Donges, J. F., Zou, Y., Marwan, N., and Kurths, J.: Complex networks in climate dynamics, Eur. Phys. J. Spec. Top., 174, 157179, 2009b.

Feldhoff, J. H., Donner, R. V., Donges, J. F., Marwan, N., and Kurths, J.: Geometric signature of complex synchronisation scenarios, Europhys. Lett., 102, 30007, doi:10.1209/02955075/102/30007, 2013.

Feng, S.: Regulation of Tibetan Plateau heating on variation of Indian summer monsoon in the last two millennia, Geophys. Res. Lett., 32, L02702, doi:10.1029/2004GL021246, 2005.

Flohn, H.: Large-scale aspects of the "summer monsoon" in south and East Asia, J. Meteorol. Soc. Jpn., 75, 180-186, 1957.

Gadgil, S.: The Indian monsoon and its variability, Annu. Rev. Earth Planet. Sci., 31, 429-467, 2003.
Gadgil, S.: Extremes of the Indian summer monsoon rainfall, ENSO and equatorial Indian Ocean oscillation, Geophys. Res. Lett., 31, L12213, doi:10.1029/2004GL019733, 2004.

GEBCO: http://www.gebco.net/data_and_products/gridded_ bathymetry_data/, last access: 21 May 2014.

Gozolchiani, A., Yamasaki, K., Gazit, O., and Havlin, S.: Pattern of climate network blinking links follows El Niño events, Europhys. Lett., 83, 28005, doi:10.1209/0295-5075/83/28005, 2008.

Gozolchiani, A., Havlin, S., and Yamasaki, K.: The Emergence of El Niño as an Autonomous Component in the Climate Network, Phys. Rev. Lett., 107, 14, doi:10.1103/PhysRevLett.107.148501, 2011.

Huffman, G. J., Bolvin, D. T., Nelkin, E. J., Wolff, D. B., Adler, R. F., Gu, G., Hong, Y., Bowman, K. P., and Stocker, E. F.: The TRMM Multisatellite Precipitation Analysis (TMPA): QuasiGlobal, Multiyear, Combined-Sensor Precipitation Estimates at Fine Scales, J. Hydrometeorol., 8, 38-55, 2007.

Kalnay, E., Kanamitsu, M., Kistler, R., Collins, W., Deaven, D., Gandin, L., Iredell, M., Saha, S., White, G., Woollen, J., Zhu, Y., Chelliah, M., Ebisuzaki, W., Higgins, W., Janowiak, J., Mo, K. C., Ropelewski, C., Wang, J., Leetmaa, A., Reynolds, R., Jenne, R., and Joseph, D.: The NCEP/NCAR 40-year reanalysis project, B. Am. Meteorol. Soc., 77, 437-440, 1996.

Krishna Kumar, K.: Advancing dynamical prediction of Indian monsoon rainfall, Geophys. Res. Lett., 32, L08704, doi:10.1029/2004GL021979, 2005.

Krishnamurti, T. N.: Tropical East-West Circulations During the Northern Summer, J. Atmos. Sci., 28, 1342-1347, 1971.

Malik, N., Marwan, N., and Kurths, J.: Spatial structures and directionalities in Monsoonal precipitation over South Asia, Nonlin. Processes Geophys., 17, 371-381, doi:10.5194/npg-17-3712010, 2010.

Malik, N., Bookhagen, B., Marwan, N., and Kurths, J.: Analysis of spatial and temporal extreme monsoonal rainfall over South Asia using complex networks, Clim. Dynam., 39, 971-987, 2011.

Martin, E., Paczuski, M., and Davidsen, J.: Interpretation of link fluctuations in climate networks during El Niño periods, Europhys. Lett., 102, 48003, doi:10.1209/0295-5075/102/48003, 2013.

Marwan, N., Donges, J. F., Zou, Y., Donner, R. V., and Kurths, J.: Complex network approach for recurrence analysis of time series, Phys. Lett. A, 373, 4246-4254, 2009.

Marwan, N., Schinkel, S., and Kurths, J.: Recurrence plots 25 years later - Gaining confidence in dynamical transitions, Europhys. Lett., 101, 20007, doi:10.1209/0295-5075/101/20007, 2013.

Molkenthin, N., Rehfeld, K., Stolbova, V., Tupikina, L., and Kurths, J.: On the influence of spatial sampling on climate networks, Nonlin. Processes Geophys., 21, 651-657, doi:10.5194/npg-21651-2014, 2014.

NCEP/NCAR: http://www.erls.noaa.gov/psd, last access: 25 February 2014.

Pai, D. and Nair, R. M.: Summer monsoon onset over Kerala: New definition and prediction, J. Earth Syst. Sci, 118, 123-135, 2009.

Paluš, M., Hartman, D., Hlinka, J., and Vejmelka, M.: Discerning connectivity from dynamics in climate networks, Nonlin. Processes Geophys., 18, 751-763, doi:10.5194/npg-18-751-2011, 2011. 
Rajagopalan, B. and Molnar, P.: Signatures of Tibetan Plateau heating on Indian summer monsoon rainfall variability, J. Geophys. Res.-Atmos., 118, 1170-1178, 2013.

Rajkumari, G. and Narasimha, R.: Statistical analysis of the position of the monsoon trough, Proc. Indian Acad. Sci., 105, 343-355, 1996.

Rao, N. G.: Variations of the SO Relationship with Summer and Winter Monsoon Rainfall over India: 1872-1993, J. Climate, 12, 3486-3495, 1999.

Rehfeld, K., Marwan, N., Breitenbach, S. F. M., Kurths, J., and Dynamics, C.: Late Holocene Asian Summer Monsoon dynamics from small but complex networks of palaeoclimate data, Clim. Dynam., doi:10.1007/s00382-012-1448-3, in press, 2012.

Revadekar, J. V. and Preethi, B.: Statistical analysis of the relationship between summer monsoon precipitation extremes and foodgrain yield over India, Int. J. Climatol., 32, 419-429, 2012.

Rheinwalt, A., Marwan, N., Kurths, J., Werner, P., and Gerstengarbe, F.-W.: Boundary effects in network measures of spatially embedded networks, Europhys. Lett., 100, 28002, doi:10.1209/0295-5075/100/28002, 2012.

Sabeerali, C. T., Rao, S. A., Ajayamohan, R. S., and Murtugudde, R.: On the relationship between Indian summer monsoon withdrawal and Indo-Pacific SST anomalies before and after 1976/1977 climate shift, Clim. Dynam., 39, 841-859, 2011.

Sankar, S., Kumar, M. R. R., Reason, C., and Paula, D.: On the Relative Roles of El Nino and Indian Ocean Dipole Events on the Monsoon Onset over Kerala, Theor. Appl. Climatol., 103, 359374, 2011.

Scarsoglio, S., Laio, F., and Ridolfi, L.: Climate dynamics: a network-based approach for the analysis of global precipitation, PloS One, 8, e71129, doi:10.1371/journal.pone.0071129, 2013.

Singh, N. and Sontakke, N. A.: On the Variability and Prediction of Rainfall in the Post-monsoon season over India, Int. J. Climatol., 19, 309-339, 1999.

Sinha, P., Mohanty, U. C., Kar, S. C., and Kumari, S.: Role of the Himalayan Orography in Simulation of the Indian Summer Monsoon using RegCM3, Pure Appl. Geophys., doi:10.1007/s00024013-0675-9, in press, 2013

Tirabassi, G. and Masoller, C.: On the effects of lag-times in networks constructed from similarities of monthly fluctuations of climate fields, Eur. Phys. Lett., 102 59003, doi:10.1209/02955075/102/59003, 2013.

TRMM: http://disc.sci.gsfc.nasa.gov/precipitation/documentation/, last access: 25 February 2014.

Tsonis, A. and Roebber, P.: The architecture of the climate network, Physica A, 333, 497-504, 2004.

Tsonis, A. A. and Swanson, K.: Topology and Predictability of El Niño and La Niña Networks, Phys. Rev. Lett., 100, 228502, doi:10.1103/PhysRevLett.100.228502, 2008.
Tsonis, A. A., Swanson, K. L., and Roebber, P. J.: What Do Networks Have to Do with Climate?, B. Am. Meteorol. Soc., 87, 585-595, 2006.

Tsonis, A. A., Swanson, K. L., and Wang, G.: On the Role of Atmospheric Teleconnections in Climate, J. Climate, 21, 2990-3001, 2008.

Tsonis, A. A., Wang, G., Swanson, K. L., Rodrigues, F. A., and Costa, L. D. F.: Community structure and dynamics in climate networks, Clim. Dynam., 37, 933-940, 2010.

Tupikina, L., Rehfeld, K., Molkenthin, N., Stolbova, V., Marwan, N., and Kurths, J.: Characterizing the evolution of climate networks, Nonlin. Processes Geophys., 21, 705-711, doi:10.5194/npg-21-705-2014, 2014.

Waliser, D. E., Jin, K., Kang, I.-S., Stern, W. F., Schubert, S. D., Wu, M. L. C., Lau, K.-M., Lee, M.-I., Krishnamurthy, V., Kitoh, A., Meehl, G. A., Galin, V. Y., Satyan, V., Mandke, S. K., Wu, G., Liu, Y., and Park, C.-K.: AGCM simulations of intraseasonal variability associated with the Asian summer monsoon, Clim. Dynam., 21, 423-446, 2003.

Wang, B.: The Asian Monsoon, Springer Praxis Books, Springer, Berlin, Germany, 2006.

Wang, Y., Gozolchiani, A., Ashkenazy, Y., Berezin, Y., Guez, O., and Havlin, S.: Dominant Imprint of Rossby Waves in the Climate Network, Phys. Rev. Lett., 111, 138501, doi:10.1103/PhysRevLett.111.138501, 2013.

Webster, P.: The Elementary Monsoon, John Wiley, New York, 32 pp., 1997.

Webster, P.: Monsoon: Processes, predictability, and the prospects for prediction, J. Geophys. Res., 103, 14451-14510, 1998.

Wu, R. and Kirtman, B. P.: On the impacts of the Indian summer monsoon on ENSO in a coupled GCM, Q. J. Roy. Meteorol. Soc. 129, 3439-3468, 2003.

Wu, R., Chen, J., and Chen, W.: Different Types of ENSO Influences on the Indian Summer Monsoon Variability, J. Climate, 25, 903-920, 2012.

Yamasaki, K., Gozolchiani, A., and Havlin, S.: Climate Networks around the Globe are Significantly Affected by El Niño, Phys Rev. Lett., 100, 228501, doi:10.1103/PhysRevLett.100.228501, 2008.

Yamasaki, K., Gozolchiani, A., Havlin, S., and Gan, R.: Climate Networks Based on Phase Synchronization Analysis Track ElNiño, in: Progress of Theoretical Physics Supplement, 178-188, doi:10.1143/PTPS.179.178, 2009.

Yatagai, A., Arakawa, O., Kamiguchi, K., and Kawamoto, H.: A 44-Year Daily Gridded Precipitation Dataset for Asia, B. Am. Meteorol. Soc., 5, 3-6, 2009. 